\title{
The default mode network as a biomarker for monitoring the therapeutic effects of meditation
}

\author{
Rozalyn Simon and Maria Engström * \\ Center for Medical Image Science and Visualization, Department of Medical and Health Sciences, Linköping University, \\ Linköping, Sweden
}

OPEN ACCESS

Edited by:

Barbara Tomasino,

University of Udine, Italy

Reviewed by:

Yi-Yuan Tang,

Texas Tech University, USA

Gaëlle Desbordes,

Harvard Medical

School/Massachusetts General

Hospital, USA

*Correspondence:

Maria Engström,

Center for Medical Image Science and Visualization, Department of Medical and Health Sciences, Linköping University, SE-581

85 Linköping, Sweden

maria.engstrom@liu.se

Specialty section:

This article was submitted to

Cognition,

a section of the journa

Frontiers in Psychology

Received: 31 October 2014 Accepted: 25 May 2015

Published: 09 June 2015

Citation:

Simon R and Engström M (2015)

The default mode network as

a biomarker for monitoring

the therapeutic effects of meditation.

Front. Psychol. 6:776.

doi: 10.3389/fpsyg.2015.00776
The default mode network (DMN) is a group of anatomically separate regions in the brain found to have synchronized patterns of activation in functional magnetic resonance imaging (fMRI). Mentation associated with the DMN includes processes such as mind wandering, autobiographical memory, self-reflective thought, envisioning the future, and considering the perspective of others. Abnormalities in the DMN have been linked to symptom severity in a variety of mental disorders indicating that the DMN could be used as a biomarker for diagnosis. These correlations have also led to the use of DMN modulation as a biomarker for assessing pharmacological treatments. Concurrent research investigating the neural correlates of meditation, have associated DMN modulation with practice. Furthermore, meditative practice is increasingly understood to have a beneficial role in the treatment of mental disorders. Therefore we propose the use of DMN measures as a biomarker for monitoring the therapeutic effects of meditation practices in mental disorders. Recent findings support this perspective, and indicate the utility of DMN monitoring in understanding and developing meditative treatments for these debilitating conditions.

Keywords: meditation, neuroimaging, default mode network, therapy, mindfulness, functional magnetic resonance imaging (fMRI), biomarker, DMN modulation

Brain activation, measured by regional blood flow, can be visualized in functional magnetic resonance imaging (fMRI) as the blood-oxygen-level-dependent (BOLD) signal. Since the early years of fMRI research, awake, restful brain activity has been used as a baseline for the measurement of specific tasks. During this baseline brain activation, the synchronous behavior of a number of anatomic regions was observed and initially identified as a network of task-specific deactivations, dubbed the default mode network (DMN; Gusnard and Raichle, 2001; Raichle et al., 2001). Later it was determined that these task specific deactivations of the $\mathrm{DMN}$ also showed patterns of coherent activation during periods of rest. These ongoing low-frequency fluctuations in the resting state consume $60-80 \%$ of the brain's energy (Shulman et al., 2004; Raichle and Mintun, 2006) and though observed by many, their significance was not initially understood (Biswal et al., 1995). The DMN became the first, and now the most extensively studied of the many known resting state functional networks. The main nodes of the DMN have been identified as the medial prefrontal cortex (mPFC), anterior and posterior cingulate cortices (ACC, PCC), precuneus (PCU), inferior parietal cortex (IPC), and lateral temporal cortex (Raichle et al., 2001; Raichle and Snyder, 2007). These primary nodes of the DMN are functionally connected, meaning they exhibit concerted fluctuations during functional tasks. The DMN's robustness has been established both functionally (Shulman et al., 1997; Gusnard and Raichle, 2001; Mazoyer et al., 2001; Raichle et al., 2001; 
Lazar et al., 2003; Harrison et al., 2008) and structurally (Shulman et al., 2004; Raichle and Mintun, 2006; Greicius et al., 2009). Network activation has been associated with specific mentation including autobiographical memory, selfreflective thought (Gusnard et al., 2001; Sheline et al., 2009), envisioning future events, mind wandering (Mason et al., 2007), and considering the thoughts and perspectives of others (Raichle et al., 2001; Raichle and Snyder, 2007; Buckner et al., 2008).

\section{The DMN as a Diagnostic Tool}

In healthy individuals, DMN activity has been anti-correlated with goal-oriented task-positive networks (TPNs; Fox et al., 2005; Kelly et al., 2008). On the other hand, abnormal DMN activity such as competitive, antagonistic DMN activation during TPN activity or changes in connectivity between subregions of the DMN - has been associated with a number of psychological disorders such as schizophrenia (Garrity, 2007; Pomarol-Clotet et al., 2008; Camchong et al., 2011; Bastos-Leite et al., 2014), epilepsy (Liao et al., 2010), anxiety (Zhao et al., 2007), depression (Sheline et al., 2009), autism (Assaf et al., 2010), attention deficit hyperactivity disorder (ADHD; Uddin et al., 2008), and Alzheimer's disease (AD; Greicius et al., 2004; Sheline and Raichle, 2013). These associations have popularized the use of DMN analysis as a method by which to study mental disorders, resulting in a growing body of literature concerning disorderspecific variations within the DMN [see reviews (Greicius, 2008; Broyd et al., 2009; Fox, 2010; Whitfield-Gabrieli and Ford, 2012)]. Some examples of network variation include failure to deactivate the DMN during tasks in both autism (Spencer et al., 2012) and depression (Grimm et al., 2008; Sheline et al., 2009); decreased DMN activity and connectivity in AD (Sorg et al., 2007; Sheline and Raichle, 2013); antagonistic activity during attention-demanding tasks in schizophrenia (WhitfieldGabrieli et al., 2009); differences in functional connectivity in both anorexia (Cowdrey et al., 2014) and autism (Assaf et al., 2010) and network inhomogeneity in ADHD (Uddin et al., 2008) and bipolar disorders (Liu et al., 2013). In some disorders such as $\mathrm{AD}$ (Sperling, 2011; Koch et al., 2012; Balthazar et al., 2014), depression (Li et al., 2013; Wise et al., 2014), and schizophrenia (Shen et al., 2014), these abnormalities of the DMN are consistent enough to be evaluated for use as diagnostic biomarkers.

Amongst these disorders, the relationship between the DMN and $\mathrm{AD}$ pathology has been the most thoroughly investigated. Anatomical regions of neuron loss and plaque deposition in $\mathrm{AD}$ overlap with regions of the DMN (Buckner et al., 2005). Greicius et al. (2004) observed a decrease in DMN activity and connectivity in patients with $\mathrm{AD}$, likely due to decreased metabolism and physiological disruptions from plaque deposition. According to these analyses, patterns of DMN disruption provide a metric by which to distinguish individual $\mathrm{AD}$ subjects from healthy elderly controls with a sensitivity of $85 \%$ and a specificity of $77 \%$ (Greicius et al., 2004). Work by Sorg et al. (2007) also found patterns of DMN disruption and attenuated activation in patients with mild cognitive impairment (MCI), supporting the use of DMN alterations for the early detection of individuals at risk for AD. Most recently, work by Balthazar et al. (2014) found that by using the PCC as a seed region for DMN functional connectivity analysis, early AD patients could be distinguished from healthy controls with a sensitivity of 77.3 and $70 \%$ specificity, indicating that DMN analysis of PCC connectivity could represent a promising biomarker for early AD diagnosis (Sheline et al., 2010b; Sheline and Raichle, 2013).

In contrast to $\mathrm{AD}$ which has regions of decreased $\mathrm{DMN}$ activity and connectivity, investigations in schizophrenia reveal increases in DMN activity during task performance as well as increased connectivity relative to controls (Garrity, 2007; Pomarol-Clotet et al., 2008; Whitfield-Gabrieli et al., 2009; Camchong et al., 2011; Bastos-Leite et al., 2014). In a number of studies, the degree of DMN disorder significantly correlated with the severity of psychological symptoms (Garrity, 2007; Whitfield-Gabrieli et al., 2009; Camchong et al., 2011). The same is true in the case of depression, where abnormal DMN activity and functional connectivity correlate with depressive rumination and symptom severity (Greicius et al., 2007; Berman et al., 2010; Sheline et al., 2010a). Many studies have now established this relationship between DMN-related abnormalities and psychological symptoms such as depressive rumination (Greicius, 2008; Broyd et al., 2009; Sheline et al., 2009; Fox, 2010; Whitfield-Gabrieli and Ford, 2012), feelings of hopelessness (Grimm et al., 2008), mind wandering (Mason et al., 2007), and poor cognitive performance (Weissman et al., 2006; Sorg et al., 2007; Sheline and Raichle, 2013) further intimating the role of the DMN in mental illness.

\section{The DMN as a Biomarker for Treatment Response}

If abnormalities of the DMN can be employed as diagnostic biomarkers or a metric of symptom severity, can the posttreatment normalization of DMN activity and connectivity also be used to evaluate treatment effectivity? Pharmacological fMRI (phfMRI) studies may be the first to provide an answer to this question (Anand et al., 2005; Sambataro et al., 2009; Di Simplicio et al., 2011; Kozel et al., 2011; Tregellas et al., 2011; Li et al., 2012; Andreescu et al., 2013; Posner et al., 2013; Smucny et al., 2014; Wang et al., 2014). For example, Tregellas et al. (2011) used the DMN as a metric in evaluating patient response to medication in schizophrenics with high posterior DMN connectivity and activity. Post-treatment, they found DMN activity resembling healthy network functioning (Tregellas et al., 2011). For the treatment of depression, Wang et al. (2014) reported changes in resting state functional connectivity resulting from the use of antidepressants. Their work also showed that reductions in functional connectivity of the dorsomedial prefrontal cortex, a subregion of the DMN (Sheline et al., 2009), significantly correlated with symptomatic improvement. For the treatment of AD, Li et al. (2012) showed that after administration of Donepezil, patients exhibited increased blood flow and functional connectivity to the PCC region of the DMN, restoring connectivity to levels resembling healthy controls. As 
a locus for measuring recovery, these changes in the DMN significantly correlated with improved cognitive performance ( $\mathrm{Li}$ et al., 2012).

The combined use of clinical evaluations with an objective measure such as DMN analysis, could provide a powerful new metric for assessing the success of differing treatments. The essential precursor to this approach is the establishment of reliable, disorder-specific differences between the DMNs of patient populations and healthy controls. In addition, there is evidence supporting the potential to further subgroup broadly diagnosed disorders based on additional DMN variations within patient populations (Lui et al., 2011; Li et al., 2013; Liu et al., 2013). Although these methods are currently being employed to evaluate pharmacological treatments for mental disorders, few have utilized DMN measures to evaluate non-pharmacological cognitive interventions such as meditation. There is a growing body of evidence indicating that meditative mindfulness practices may provide a promising avenue for the treatment of many of the mental disorders discussed above (see reviews Baer, 2006; Chiesa and Serretti, 2009, 2011; Chiesa, 2010; Keng et al., 2011). In this perspective, we propose the use of DMN analysis as an additional objective metric or biomarker for monitoring the therapeutic effects of meditation in mental disorders.

\section{Meditation and Modulation of the DMN}

As research strengthens the link between anatomical regions of the DMN and psychological processes such as self-reflection, rumination, and mind wandering, much interest has been directed toward non-pharmacological means of altering patterns of behavior within this network. Meta-analyses examining the specific neurocorrelates of meditation have shown reductions in DMN activity as a primary outcome of mindfulness meditation practices (Tomasino et al., 2012, 2014). Results from a recent study by Garrison et al. (2015) indicate that meditation is associated with reduced activations in the DMN relative to an active association task for meditators as compared to controls.

For depression, reduced DMN activity in regions associated with subjective evaluation of emotional experience and selfreferencing are thought to allow the individual to experience the present moment with greater objectivity, reducing bias or valuation (Ives-Deliperi et al., 2011). A reduction in self-referential evaluation trains the individual to abandon emotionally charged assessments of their internal and external world, thus altering patterns of self-judgment and value assignment (Farb et al., 2007, 2010). Shapiro's model of mindfulness calls this "re-perceiving" and notes its likeness to psychological models of decentering (Safran, 1990) and detachment (Bohart, 1983). In psychotherapy, dis-identification refers to a process where the individual becomes capable of reappraisal by distinguishing thoughts from feelings. Likewise, through meditation, the patient's self-perception changes from an enduring entity to a transient entity. In this way the patient becomes less fixated and less likely to ruminate on faults and mistakes (Jackson et al., 2000; Gross, 2002).
Additional psychological benefits of reduced DMN interferences include improvements in attentional control (Lutz et al., 2008; Hasenkamp and Barsalou, 2012; Hasenkamp et al., 2012) by reducing DMN/TPN competition, commonly associated with mental disorders such as schizophrenia (Whitfield-Gabrieli et al., 2009) and ADHD (Sonuga-Barke and Castellanos, 2007; Uddin et al., 2008). These studies associating psychological changes with DMN modulation as an outcome of meditative practice represent only a few of the results motivating recent trends in $\mathrm{fMRI}$ research (see Table 1).

\section{Mindfulness Meditation as a Clinical Therapy}

Westernized forms of meditation stemming from Buddhist traditions have popularized the concept of "mindfulness" as a therapeutic. These Mindfulness methods have been beneficial in the treatment of psychological disorders such as schizophrenia (Chien and Thompson, 2014), depression (Teasdale et al., 2000; Ma and Teasdale, 2004; Eisendrath et al., 2008; Kuyken et al., 2008), addiction (Bowen et al., 2014), alcoholism (Witkiewitz et al., 2005; Garland et al., 2010), anxiety (Grossman et al., 2004; Baer, 2006; Ludwig and Kabat-Zinn, 2008; Shen et al., 2014), MCI (Wells et al., 2013a), and ADHD (Zylowska et al., 2007; Smalley et al., 2009). Preliminary findings suggest the effects of meditation include increases in emotion regulation (Lutz et al., 2014), memory and cognition (Zeidan et al., 2010), self-regulation (Tang et al., 2014), awareness and self-perception (Hölzel et al., 2011b), as well as gray and white matter differences in experienced meditators (Luders et al., 2009; Hölzel et al., 2011a; Tang et al., 2012, 2015; Fox et al., 2014). Mindfulnessbased stress reduction (MBSR) programs incorporate meditation techniques with group meetings, simple yoga, and home assignments (Teasdale et al., 2000; Kabat-Zinn, 2003). This approach allows for broad applications as these programs are standardized and have no religious associations, making them suitable for researchers and clinicians. Though the religious associations of traditional forms of meditative practice have been reduced through such westernized approaches, the number of variables in Mindfulness programs still confound evaluation of clinical efficacy (Chiesa and Serretti, 2009, 2011; Chiesa, 2010). Understanding the specific mechanisms of mindfulness that lead to multi-dimensional mental health outcomes is no trivial task. The reduction of mindfulness into measurable components has been suggested by many resulting in a number of different psychometric assessments (Brown, 2004; Grossman et al., 2004; Feldman et al., 2006; Lau et al., 2006; Baer et al., 2008). In addition to the identification of specific outcomes, meditation efficacy studies have also proven challenging due to variations in meditative practice, length of time practiced, lack of controls, and the inability to conduct double-blind studies - a fault inherent to all therapy efficacy studies. Recent studies using active controls for MBSR programs (MacCoon et al., 2012, 2014; Rosenkranz et al., 2013) have improved upon previous investigations which only used wait list control groups. These types of experimental improvements are necessary to distinguish the specific effects 
TABLE 1 | Summary of functional magnetic resonance imaging (fMRI) findings on default mode network (DMN) modulation associated with meditation practices.

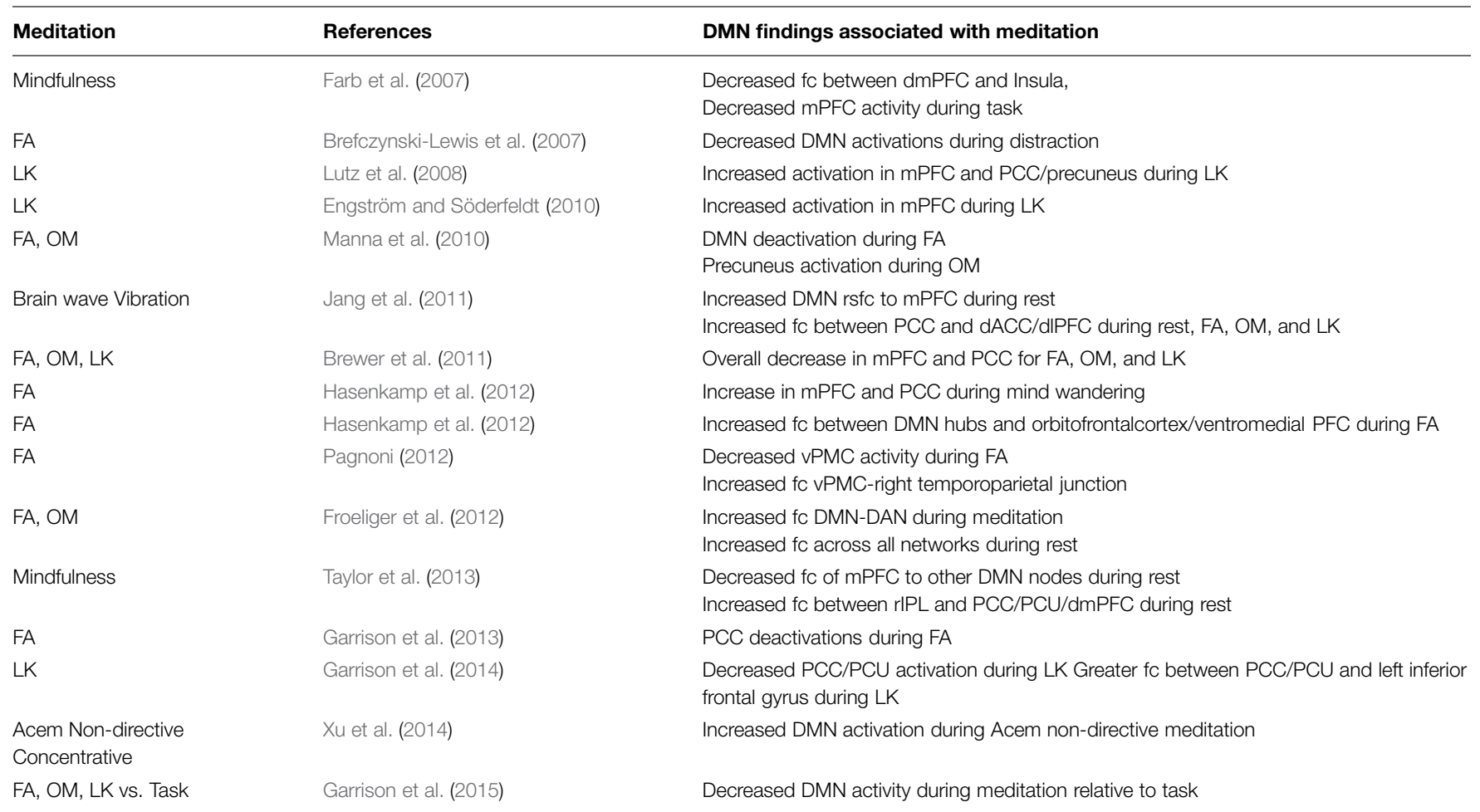

rs, resting state; fc, functional connectivity; d, dorsal; dm, dorsal medial; dl, dorsal lateral; vPMC, ventral posteromedial cortex; DAN, dorsal attention network; rIPL, right inferior parietal lobe.

resulting from meditation training versus group therapy or other forms of general behavioral modification. These studies highlight the need for more controlled experimental design and specific biomarkers such as the DMN by which to follow the underlying neurological changes associated with meditation training.

As with all emerging fields, consensus building to bridge areas of specialization requires time and a sufficient amount of preliminary data. These issues are widely recognized, leading to the development of a more defined theoretical framework (Hölzel et al., 2011b) and improved operational definitions (Bishop et al., 2004; Shapiro et al., 2006). These improvements help to guide fMRI experiment design in order to provide objective, empirical evaluation of this previously elusive, highly internalized process.

Despite these improvements, variations in meditative methods persist as a barrier in the advancement of this line of research. A majority of the techniques used in experimental approaches are based in Buddhist traditions. Three of the fundamental practices central to nearly all Buddhist meditation have been generalized to include other traditions, and redefined by some researchers as focused attention (FA), open monitoring (OM), and loving kindness (LK), respectively (Lutz et al., 2004, 2008). These are well-developed techniques commonly encountered in research literature which will only briefly be described here, but whose histories, grounding philosophies, and complete descriptions are reviewed extensively by Lutz, Dunne, and Davidson (Lutz et al., 2007). While it is essential for general research purposes that FA, OM, and LK be investigated separately in terms of their DNM-associated neurocorrelates, we hypothesize that the synergy of all three practices is key to cultivating "equanimity" and is essential when considering meditation as a form of general therapy for mental disorders (Desbordes et al., 2014).

During FA, the participant sits calmly with all attention focused on some object of interest, commonly the breath. Each time the mind begins to wander, the meditator is trained to guide the focus of attention back with non-judgmental awareness. This practice is meant to develop the individual's meta-awareness, focus, and attention - skills required for all subsequent meditative practices. FA practice can be viewed as mental training to reduce the competitive distraction and daydreaming activities of the DMN. Hasenkamp et al. (2012) investigated the neurocorrelates of fluctuating FA phases in experienced meditators. Participants were asked to maintain FA on breath and instructed to press a button when they realized their attention had wandered. Activity could be detected in brain regions associated with FA, mind wandering, and awareness of mind wandering. DMN activations were correlated with periods of mind wandering, contrasting with attentional activations during awareness, shifting, and maintaining FA. A follow-up resting state study revealed that connectivity in attentional networks correlated with hours of meditative experience, indicating that the repeated process of refocusing the attention leads to increases in attentional control and reduced distractibility of the practitioner in everyday life (Hasenkamp and Barsalou, 2012). This study thus supports the 


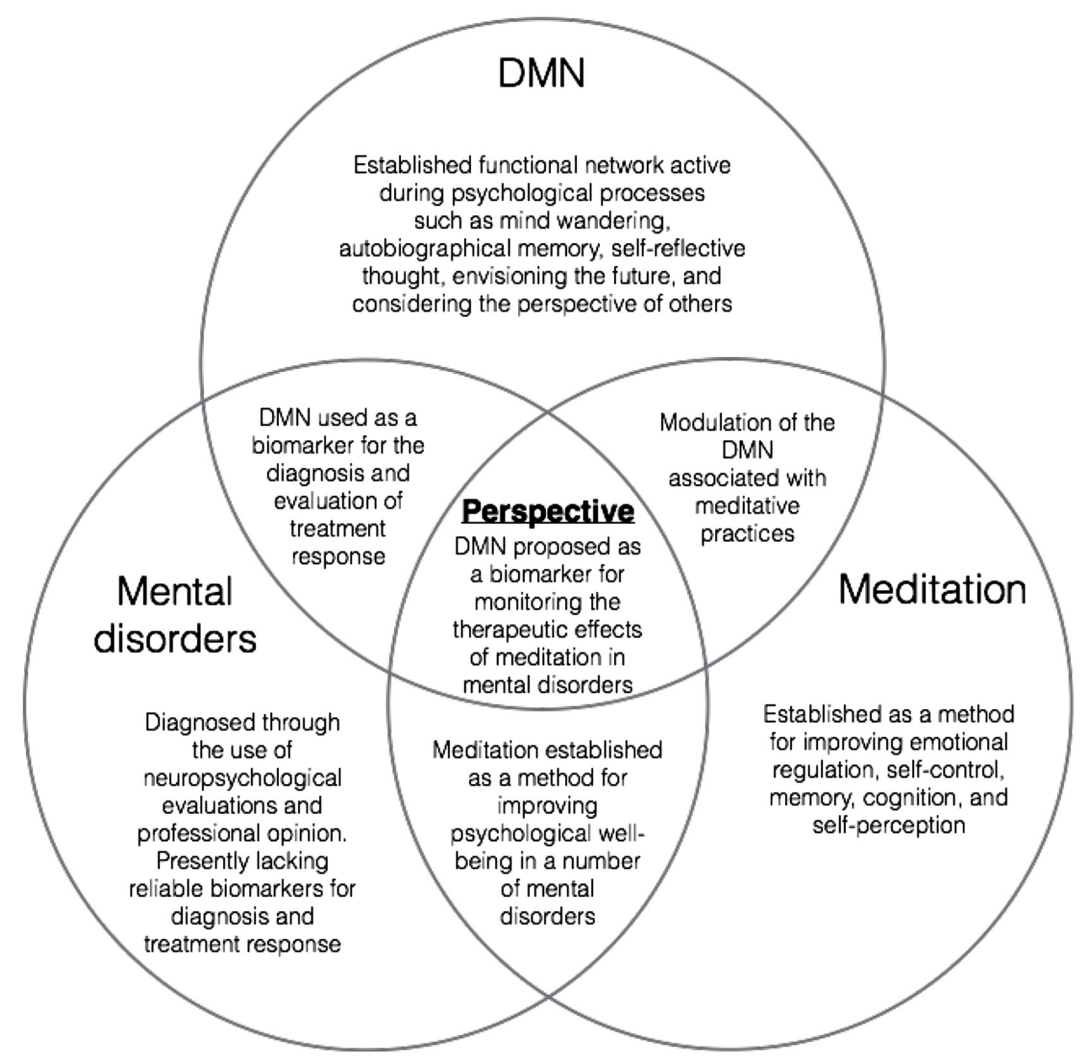

FIGURE 1 | A visual representation of overlapping areas of research converging on the present perspective.

use of FA as a form of training to reduce DMN/TPN competition. Work by Brefczynski-Lewis et al. (2007) supports this hypothesis of decreased distractibility with increased meditative practice. They found that while listening to distractive sounds, relative to novices, expert meditators had less activation in regions within the DMN and more activation in regions related to response inhibition and attention. These results support the hypothesis that the mental health benefits of FA meditation are a result of the cultivation of attentional control through trained disengagement of the DMN, reducing related mentation associated with rumination (Berman et al., 2010; Sheline et al., 2010a), mind wandering (Mason et al., 2007), and unhappiness (Killingsworth and Gilbert, 2010). The practice of FA lays a foundation for all subsequent techniques, as distractibility is detrimental to meditative practice.

The second common technique of mindfulness practice is $\mathrm{OM}$, where the meditator directs their attention toward the non-judgmental awareness of internal and external physical sensations. The meditator's attention is expected to wander, yet the individual neither cultivates nor forcefully suppresses distracting thoughts. In OM, the meditator is instructed to nonjudgmentally observe thoughts and sensations while remaining unreactive. This trains the individual to reduce emotional reactivity and volatility. The objective in $\mathrm{OM}$ is to develop insight into the subjective and constantly changing nature of reality while maintaining present awareness. For beginners, establishing oneself in OM meditation often begins with some form of FA. However, this requirement is thought to depend on hours of experience (Brewer et al., 2011). Manna et al. (2010) observed an increase in activation of the PCU, a hub of the DMN, during OM when compared to FA. This study, which investigated differences between OM and FA meditation, found that when compared to novices, expert practitioners' patterns of brain activity during $\mathrm{OM}$ resembled their normal resting state activity. They postulated that with extended practice, this state of non-judgmental awareness or "mindfulness" becomes the intrinsic or default mode of brain activity (Manna et al., 2010).

Although some amount of mind wandering during OM is accepted, identifying with, attaching to, or engaging in these thoughts is discouraged. We suggest that in this way, one develops an ability to be simultaneously present and aware of physical stimuli while engaging in DMNassociated creative processes such as reflection and mind wandering without emotional attachment or reactivity. Put another way, training to suppress the DMN through FA allows for the gradual and controlled reintroduction of DMN-related activities in $\mathrm{OM}$ with an enhanced metacognition, abrogating uncontrolled emotional reactivity and self-identification.

The third common element of most Buddhist meditation practices is $\mathrm{LK}$, or $\mathrm{LK}$, where the meditator focuses on feelings of LK and compassion toward others. During LK 
meditation, all forms of stimuli can be called upon, such as visualization, memory, self-reflection, and auditory mantras, in an effort to dissolve feelings of separation, isolation, and conflict between the meditator and others. This process utilizes skills developed in both FA and OM meditation. This element of Buddhist practice was not included in the proposed operational definition of mindfulness by Bishop et al. (2004). For treatment of psychological disorders however, there is a strong argument for the inclusion of this practice as the objective is to develop empathy and compassion for oneself and others (Hofmann et al., 2011; Farb et al., 2012; Shonin et al., 2014). A study by Garrison et al. (2014) showed that DMN connectivity was reduced during LK meditation, possibly as a result of reduced self-referential processing. Related findings investigating the neurocorrelates of empathy and forgiveness have observed DMN activations in the PCC/PCU (Farrow et al., 2001; Völlm et al., 2006). Engström and Söderfeldt (2010) found activations in the mPFC during LK meditation which others propose reflects processing which is important for experiencing empathy (Seitz et al., 2006). The basic link between the practice of empathy and the mental processes associated with the DMN - considering the perspective of others, autobiographical memory, and self-referential thought - seems self-evident. However, much work remains to define the specific changes in the DMN resulting from this form of meditative training.

Across all three types of meditation, Brewer et al. (2011) observed that two primary nodes of the DMN, the PCC and $\mathrm{mPFC}$, were less active in experienced meditators compared to novices. Thus, for experienced meditators relative to novices, DMN processes such as mind wandering are reduced even before task engagement. In addition, they found increased functional connectivity in experienced meditators between the PCC and task-positive regions during all conditions including rest, indicating trait-based neural differences in long-term meditators. Like Manna et al. (2010) they suggest that longterm meditative practice may transform the individual's intrinsic resting state into a more "present-centered" meditative state (Brewer et al., 2011).

\section{First Steps: Clinical Trials}

Taken together, these studies provide evidence to support further investigation into the use of DMN metrics for the evaluation of meditative therapies (see Figure 1). Indeed, controlled studies correlating resting state DMN modulation with neuropsychological measures for the evaluation of Mindfulness therapies are emerging with promising results. Wells et al. (2013b) conducted a pilot study to investigate the effects of MBSR training on a group of mild cognitively impaired (MCI) patients at risk for $\mathrm{AD}$. The results indicated that after MBSR training, MCI patients had increased DMN connectivity in the PCC, mPFC, and hippocampus, relative to controls. They also investigated changes in the volume of the hippocampus, a region known to atrophy in MCI/AD, and found trends toward less hippocampal atrophy in MBSR-trained patients relative to controls. As a result of these findings they suggest that DMN connectivity could be used as a non-invasive biomarker for assessing the impact of mindfulness interventions in MCI patients, though larger studies need to be conducted (Wells et al., 2013b).

Ives-Deliperi et al. (2013) conducted a controlled study investigating the effects of Mindfulness-based Cognitive Therapy (MBCT) in bipolar disorder. Previous to treatment, bipolar patients had significantly higher levels of stress and anxiety, lower scores on working memory tasks, and decreases in mPFC signals during task relative to healthy controls. After treatment, they observed BOLD increases in the $\mathrm{mPFC}$ and posterior parietal lobe during task, significant increases in mindfulness measures and working memory, as well as decreases in anxiety and emotional dysregulation. Region of interest analysis verified a correlation between mindfulness measures and MPFC increases in BOLD signals. This study provides additional support that the DMN represents a suitable network by which to assess the effects of meditative therapies in the treatment of mental disorders (Ives-Deliperi et al., 2013).

\section{Future Perspectives}

These recent findings demonstrate use of the DMN as a potentially useful clinical tool for evaluating the therapeutic effects of meditation. Research to establish disorder-specific DMN irregularities is a necessary first step. Determining DMN differences relative to healthy controls allows for an objective measure of patient recovery or return to control-like activity and connectivity within the DMN. Correlation with neuropsychological tools for measuring symptomatic changes and cognitive improvement will help to guide the development of this emerging tool and to define its significance. However, many experimental design issues still confound the evaluation of clinical efficacy (Tang et al., 2015). First, reducing the number of coinciding therapies in Mindfulness programs and having proper control groups is essential. Documenting explicit instructions for the meditation practice will also be important for comparative studies and meta-analysis. Future studies could also include analysis of the dynamic functional connectivity associated with mental disorders and treatment response. This may allow for further subgrouping under broad diagnoses and predictions concerning treatment outcomes. Although the DMN is the best studied of the resting state networks, the analysis of other networks should also be investigated (Froeliger et al., 2012). In addition, the development and incorporation of new neuropsychological metrics - such as "equanimity" outcomes with resting state correlates will provide new tools for assessment (Desbordes et al., 2014). Finally, finding ways to integrate objective data and subjective patient reporting will be useful in understanding patient experiences associated with meditative practices (Garrison et al., 2013; Brewer and Garrison, 2014; Hasenkamp, 2014). It seems fitting that a method as internalized as meditation would be useful in treating conditions associated with neural processes so deeply intrinsic as to be called the "default mode" of brain function. 


\section{References}

Anand, A., Li, Y., Wang, Y., Wu, J., Gao, S., Bukhari, L., et al. (2005). Antidepressant effect on connectivity of the mood-regulating circuit: an fMRI study. Neuropsychopharmacology 30, 1334-1344. doi: 10.1038/sj.npp.1 300725

Andreescu, C., Tudorascu, D. L., Butters, M. A., Tamburo, E., Patel, M., Price, J., et al. (2013). Resting state functional connectivity and treatment response in late-life depression. Psychiatry Res. Neuroimag. 214, 313-321. doi: 10.1016/j.pscychresns.2013.08.007

Assaf, M., Jagannathan, K., Calhoun, V. D., Miller, L., Stevens, M. C., Sahl, R., et al. (2010). Abnormal functional connectivity of default mode subnetworks in autism spectrum disorder patients. Neuroimage 53, 247-256. doi: 10.1016/j.neuroimage.2010.05.067

Baer, R. A. (2006). Mindfulness training as a clinical intervention: a conceptual and empirical review. Clin. Psychol. Sci. Practice 10, 125-143. doi: 10.1093/clipsy.bpg015

Baer, R. A., Smith, G. T., Lykins, E., Button, D., Krietemeyer, J., Sauer, S., et al. (2008). Construct validity of the five facet mindfulness questionnaire in meditating and non-meditating samples. Assessment 15, 329-342. doi: 10.1177/1073191107313003

Balthazar, M. L. F., de Campos, B. M., Franco, A. R., Damasceno, B. P., and Cendes, F. (2014). Whole cortical and default mode network mean functional connectivity as potential biomarkers for mild Alzheimer's disease. Psychiatry Res. 221, 37-42. doi: 10.1016/j.pscychresns.2013.10.010

Bastos-Leite, A. J., Ridgway, G. R., Silveira, C., Norton, A., Reis, S., and Friston, K. J. (2014). Dysconnectivity within the default mode in first-episode schizophrenia: a stochastic dynamic causal modeling study with functional magnetic resonance imaging. Schizophr. Bull. 1, 144-153. doi: 10.1093/schbul/ sbu080

Berman, M. G., Peltier, S., Nee, D. E., Kross, E., Deldin, P. J., and Jonides, J. (2010). Depression, rumination and the default network. Soc. Cogn. Affect. Neurosci. 6, 548-555. doi: 10.1093/scan/nsq080

Bishop, S. R., Lau, M., Shapiro, S., Carlson, L., Anderson, N. D., Carmody, J., et al. (2004). Mindfulness: a proposed operational definition. Clin. Psychol. Sci. Practice 11, 230-241. doi: 10.1093/clipsy.bph077

Biswal, B., Zerrin Yetkin, F., Haughton, V. M., and Hyde, J. S. (1995). Functional connectivity in the motor cortex of resting human brain using echo-planar mri. Magn. Reson. Med. 34, 537-541. doi: 10.1002/mrm.19103 40409

Bohart, A. (1983). Detachment: a variable common to many psychotherapies? Paper Presented at the 63rd Annual Convention of the Western Psychological Association, San Francisco, CA.

Bowen, S., Witkiewitz, K., Clifasefi, S. L., Grow, J., Chawla, N., Hsu, S. H., et al. (2014). Relative efficacy of mindfulness-based relapse prevention, standard relapse prevention, and treatment as usual for substance use disorders: a randomized clinical trial. JAMA Psychiatry 71, 547-556. doi: 10.1001/jamapsychiatry.2013.4546

Brefczynski-Lewis, J. A., Lutz, A., Schaefer, H. S., Levinson, D. B., and Davidson, R. J. (2007). Neural correlates of attentional expertise in long-term meditation practitioners. Proc. Natl. Acad. Sci. U.S.A. 104, 11483-11488. doi: 10.1073/pnas.0606552104

Brewer, J. A., and Garrison, K. A. (2014). The posterior cingulate cortex as a plausible mechanistic target of meditation: findings from neuroimaging. Ann. N. Y. Acad. Sci. 1307, 19-27. doi: 10.1111/nyas.12246

Brewer, J. A., Worhunsky, P. D., Gray, J. R., Tang, Y.-Y., Weber, J., and Kober, H. (2011). Meditation experience is associated with differences in default mode network activity and connectivity. Proc. Natl. Acad. Sci. U.S.A. 108, 2025420259. doi: 10.1073/pnas.1112029108/-/DCSupplemental

Brown, K. W. (2004). Perils and promise in defining and measuring mindfulness: observations from experience. Clin. Psychol. Sci. Practice 11, 242-248. doi: 10.1093/clipsy/bph078

Broyd, S. J., Demanuele, C., Debener, S., Helps, S. K., James, C. J., and Sonuga-Barke, E. J. S. (2009). Default-mode brain dysfunction in mental disorders: a systematic review. Neurosci. Biobehav. Rev. 33, 279-296. doi: 10.1016/j.neubiorev.2008.09.002

Buckner, R. L., Andrews Hanna, J. R., and Schacter, D. L. (2008). The brain's default network. Ann. N. Y. Acad. Sci. 1124, 1-38. doi: 10.1196/annals.1440.011
Buckner, R. L., Snyder, A. Z., Shannon, B. J., LaRossa, G., Sachs, R., Fotenos, A. F., et al. (2005). Molecular, structural, and functional characterization of Alzheimer's disease: evidence for a relationship between default activity, amyloid, and memory. J. Neurosci. 25, 7709-7717. doi: 10.1523/JNEUROSCI.2177-05.2005

Camchong, J., MacDonald, A. W., Bell, C., Mueller, B. A., and Lim, K. O. (2011). Altered functional and anatomical connectivity in schizophrenia. Schizophr. Bull. 37, 640-650. doi: 10.1093/schbul/sbp131

Chien, W. T., and Thompson, D. R. (2014). Effects of a mindfulness-based psychoeducation programme for Chinese patients with schizophrenia: 2-year follow-up. Br. J. Psychiatry 205, 52-59. doi: 10.1192/bjp.bp.113.134635

Chiesa, A. (2010). Vipassana meditation: systematic review of current evidence. J. Altern. Complement. Med. 16, 37-46. doi: 10.1089/acm. 2009.0362

Chiesa, A., and Serretti, A. (2009). A systematic review of neurobiological and clinical features of mindfulness meditations. Psychol. Med. 40, 1239-1252. doi: $10.1017 /$ S0033291709991747

Chiesa, A., and Serretti, A. (2011). Mindfulness based cognitive therapy for psychiatric disorders: a systematic review and meta-analysis. Psychiatry Res. 187, 441-453. doi: 10.1016/j.psychres.2010.08.011

Cowdrey, F. A., Filippini, N., Park, R. J., Smith, S. M., and McCabe, C. (2014). Increased resting state functional connectivity in the default mode network in recovered anorexia nervosa. Hum. Brain Mapp. 35, 483-491. doi: 10.1002/hbm.22202

Desbordes, G., Gard, T., Hoge, E. A., Hölzel, B. K., Kerr, C., Lazar, S. W., et al. (2014). Moving beyond mindfulness: defining equanimity as an outcome measure in meditation and contemplative research. Mindfulness 6, 1-17.

Di Simplicio, M., Norbury, R., and Harmer, C. J. (2011). Short-term antidepressant administration reduces negative self-referential processing in the medial prefrontal cortex in subjects at risk for depression. Mol. Psychiatry 17, 503-510. doi: $10.1038 / \mathrm{mp} .2011 .16$

Eisendrath, S. J., Delucchi, K., Bitner, R., Fenimore, P., Smit, M., and McLane, M. (2008). Mindfulness-based cognitive therapy for treatmentresistant depression: a pilot study. Psychother. Psychosomat. 77, 319-320. doi: $10.1159 / 000142525$

Engström, M., and Söderfeldt, B. (2010). Brain activation during compassion meditation: a case study. J. Altern. Complement. Med. 16, 597-599. doi: 10.1089/acm.2009.0309

Farb, N. A. S., Anderson, A. K., Mayberg, H., Bean, J., McKeon, D., and Segal, Z. V. (2010). Minding one's emotions: mindfulness training alters the neural expression of sadness. Emotion 10, 25-33. doi: 10.1037/a0017151

Farb, N. A., Anderson, A. K., and Segal, Z. V. (2012). The mindful brain and emotion regulation in mood disorders. Can. J. Psychiatry 57, 70.

Farb, N. A. S., Segal, Z. V., Mayberg, H., Bean, J., McKeon, D., Fatima, Z., et al. (2007). Attending to the present: mindfulness meditation reveals distinct neural modes of self-reference. Soc. Cogn. Affect. Neurosci. 2, 313-322. doi: 10.1093/scan/nsm030

Farrow, T. F., Zheng, Y., Wilkinson, I. D., Spence, S. A., Deakin, J. W., Tarrier, N., et al. (2001). Investigating the functional anatomy of empathy and forgiveness. Neuroreport 12, 2433-2438. doi: 10.1097/00001756-200108080-00029

Feldman, G., Hayes, A., Kumar, S., Greeson, J., and Laurenceau, J.-P. (2006). Mindfulness and emotion regulation: the development and initial validation of the cognitive and affective mindfulness scale-revised (CAMSR). J. Psychopathol. Behav. Assess. 29, 177-190. doi: 10.1007/s10862-0069035-8

Fox, K. C. R., Nijeboer, S., Dixon, M. L., Floman, J. L., Ellamil, M., Rumak, S. P., et al. (2014). Is meditation associated with altered brain structure? A systematic review and meta-analysis of morphometric neuroimaging in meditation practitioners. Neurosci. Biobehav. Rev. 43, 48-73. doi: 10.1016/j.neubiorev.2014.03.016

Fox, M. D. (2010). Clinical applications of resting state functional connectivity. Front. Syst. Neurosci. 4:19. doi: 10.3389/fnsys.2010.00019

Fox, M. D., Snyder, A. Z., Vincent, J. L., Corbetta, M., Van Essen, D. C., and Raichle, M. E. (2005). The human brain is intrinsically organized into dynamic, anticorrelated functional networks. Proc. Natl. Acad. Sci. U.S.A. 102, 9673-9678. doi: 10.1073/pnas.0504136102

Froeliger, B., Garland, E. L., Kozink, R. V., Modlin, L. A., Chen, N.-K., McClernon, F. J., et al. (2012). Meditation-state functional connectivity (msFC): 
strengthening of the dorsal attention network and beyond. Evid. Based Complement. Altern. Med. 2012, 1-9. doi: 10.1007/s00221-008-1353-5

Garland, E. L., Gaylord, S. A., Boettiger, C. A., and Howard, M. O. (2010). Mindfulness training modifies cognitive, affective, and physiological mechanisms implicated in alcohol dependence: results of a randomized controlled pilot trial. J. Psychoactive Drugs 42, 177-192. doi: 10.1080/02791072.2010.10400690

Garrison, K. A., Scheinost, D., Constable, R. T., and Brewer, J. A. (2014). BOLD signal and functional connectivity associated with loving kindness meditation. Brain Behav. 4, 337-347. doi: 10.1002/brb3.219

Garrison, K. A., Scheinost, D., Worhunsky, P. D., Elwafi, H. M., Thornhill, T. A. IV, Thompson, E., et al. (2013). Real-time fMRI links subjective experience with brain activity during focused attention. Neuroimage 81, 110-118. doi: 10.1016/j.neuroimage.2013.05.030

Garrison, K. A., Zeffiro, T. A., Scheinost, D., Constable, R. T., and Brewer, J. A. (2015). Meditation leads to reduced default mode network activity beyond an active task. Cogn. Affect. Behav. Neurosci. doi: 10.3758/s13415-015-0358-3 [Epub ahead of print].

Garrity, A. (2007). Aberrant "default mode" functional connectivity in schizophrenia. Am. J. Psychiatry 164, 450. doi: 10.1176/appi.ajp.16 4.3.450

Greicius, M. (2008). Resting-state functional connectivity in neuropsychiatric disorders. Curr. Opin. Neurol. 21, 424-430. doi: 10.1097/WCO.0b013e328306f2c5

Greicius, M. D., Flores, B. H., Menon, V., Glover, G. H., Solvason, H. B., Kenna, H., et al. (2007). Resting-state functional connectivity in major depression: abnormally increased contributions from subgenual cingulate cortex and thalamus. Biol. Psychiatry 62, 429-437. doi: 10.1016/j.biopsych.2006. 09.020

Greicius, M. D., Srivastava, G., Reiss, A. L., and Menon, V. (2004). Defaultmode network activity distinguishes Alzheimer's disease from healthy aging: evidence from functional MRI. Proc. Natl. Acad. Sci. U.S.A. 101, 4637-4642. doi: 10.1073/pnas.0308627101

Greicius, M. D., Supekar, K., Menon, V., and Dougherty, R. F. (2009). Restingstate functional connectivity reflects structural connectivity in the default mode network. Cereb. Cortex 19, 72-78. doi: 10.1093/cercor/bhn059

Grimm, S., Boesiger, P., Beck, J., Schuepbach, D., Bermpohl, F., Walter, M., et al. (2008). Altered negative BOLD responses in the default-mode network during emotion processing in depressed subjects. Neuropsychopharmacology 34 , 932-843. doi: 10.1038/npp.2008.81

Gross, J. J. (2002). Emotion regulation: affective, cognitive, and social consequences. Psychophysiology 39, 281-291. doi: 10.1017/S00485772013 93198

Grossman, P., Niemann, L., Schmidt, S., and Walach, H. (2004). Mindfulnessbased stress reduction and health benefits. J. Psychosom. Res. 57, 35-43. doi: 10.1016/S0022-3999(03)00573-7

Gusnard, D. A., Akbudak, E., Shulman, G. L., and Raichle, M. E. (2001). Medial prefrontal cortex and self-referential mental activity: relation to a default mode of brain function. Proc. Natl. Acad. Sci. U.S.A. 98, 4259-4264. doi: 10.1073/pnas.071043098

Gusnard, D. A., and Raichle, M. E. (2001). Searching for a baseline: functional imaging and the resting human brain. Nat. Rev. Neurosci. 2, 685-694. doi: $10.1038 / 35094500$

Harrison, B. J., Pujol, J., López-Solà, M., Hernández-Ribas, R., Deus, J., Ortiz, H., et al. (2008). Consistency and functional specialization in the default mode brain network. Proc. Natl. Acad. Sci. U.S.A. 105, 9781-9786. doi: 10.1073/pnas.0711791105

Hasenkamp, W. (2014). "Using first-person reports during meditation to investigate basic cognitive experience," in Meditation - Neuroscientific Approaches and Philosophical Implications, eds S. Schmidt and H. Walach (Berlin: Springer), 75-93.

Hasenkamp, W., and Barsalou, L. W. (2012). Effects of meditation experience on functional connectivity of distributed brain networks. Front. Hum. Neurosci. 6:38. doi: $10.3389 /$ fnhum. 2012.00038

Hasenkamp, W., Wilson-Mendenhall, C. D., Duncan, E., and Barsalou, L. W. (2012). Mind wandering and attention during focused meditation: a finegrained temporal analysis of fluctuating cognitive states. Neuroimage 59, 750760. doi: 10.1016/j.neuroimage.2011.07.008
Hofmann, S. G., Grossman, P., and Hinton, D. E. (2011). Loving-kindness and compassion meditation: potential for psychological interventions. Clin. Psychol. Rev. 31, 1126-1132. doi: 10.1016/j.cpr.2011.07.003

Hölzel, B. K., Carmody, J., Vangel, M., Congleton, C., Yerramsetti, S. M., Gard, T., et al. (2011a). Mindfulness practice leads to increases in regional brain gray matter density. Psychiatry Res. Neuroimag. 191, 36-43. doi: 10.1016/j.pscychresns.2010.08.006

Hölzel, B. K., Lazar, S. W., Gard, T., Schuman-Olivier, Z., Vago, D. R., and Ott, U. (2011b). How does mindfulness meditation work? Proposing mechanisms of action from a conceptual and neural perspective. Perspect. Psychol. Sci. 6, 537-559. doi: 10.1177/1745691611419671

Ives-Deliperi, V. L., Howells, F., Stein, D. J., Meintjes, E. M., and Horn, N. (2013). The effects of mindfulness-based cognitive therapy in patients with bipolar disorder: a controlled functional MRI investigation. J. Affect. Disord. 150, 1152-1157. doi: 10.1016/j.jad.2013.05.074

Ives-Deliperi, V. L., Solms, M., and Meintjes, E. M. (2011). The neural substrates of mindfulness: an fMRI investigation. Soc. Neurosci. 6, 231-242. doi: 10.1080/17470919.2010.513495

Jackson, D. C., Malmstadt, J. R., Larson, C. L., and Davidson, R. J. (2000). Suppression and enhancement of emotional responses to unpleasant pictures. Psychophysiology 37, 515-522. doi: 10.1111/1469-8986.3740515

Jang, J. H., Jung, W. H., Kang, D.-H., Byun, M. S., Kwon, S. J., Choi, C. H., et al. (2011). Increased default mode network connectivity associated with meditation. Neurosci. Lett. 487, 358-362. doi: 10.1016/j.neulet.2010. 10.056

Kabat-Zinn, J. (2003). Mindfulness-based stress reduction (MBSR). Construct. Hum. Sci. 8, 73-107.

Kelly, A. C., Uddin, L. Q., Biswal, B. B., Castellanos, F. X., and Milham, M. P. (2008). Competition between functional brain networks mediates behavioral variability. Neuroimage 39, 527-537. doi: 10.1016/j.neuroimage.2007 .08 .008

Keng, S.-L., Smoski, M. J., and Robins, C. J. (2011). Effects of mindfulness on psychological health: a review of empirical studies. Clin. Psychol. Rev. 31, 1041-1056. doi: 10.1016/j.cpr.2011.04.006

Killingsworth, M. A., and Gilbert, D. T. (2010). A wandering mind is an unhappy mind. Science 330, 932-932. doi: 10.1126/science.1192439

Koch, W., Teipel, S., Mueller, S., Benninghoff, J., Wagner, M., Bokde, A. L., et al. (2012). Diagnostic power of default mode network resting state fMRI in the detection of Alzheimer's disease. Neurobiol. Aging 33, 466-478. doi: 10.1016/j.neurobiolaging.2010.04.013

Kozel, F. A., Rao, U., Lu, H., Nakonezny, P. A., Grannemann, B., McGregor, T., et al. (2011). Functional connectivity of brain structures correlates with treatment outcome in major depressive disorder. Front. Psychiatry 2:7. doi: $10.3389 /$ fpsyt.2011.00007

Kuyken, W., Byford, S., Taylor, R. S., Watkins, E., Holden, E., White, K., et al. (2008). Mindfulness-based cognitive therapy to prevent relapse in recurrent depression. J. Consult. Clin. Psychol. 76, 966-978. doi: 10.1037/a0013786

Lau, M. A., Bishop, S. R., Segal, Z. V., Buis, T., Anderson, N. D., Carlson, L., et al. (2006). The toronto mindfulness scale: development and validation. J. Clin. Psychol. 62, 1445-1467. doi: 10.1002/jclp.20326

Lazar, S. W., Kerr, C. E., Wasserman, R. H., Gray, J. R., Greve, D. N., Treadway, M. T., et al. (2003). Functional connectivity in the resting brain: a network analysis of the default mode hypothesis. Proc. Natl. Acad. Sci. U.S.A. 100, 253-258. doi: 10.1073/pnas.0135058100

Li, B., Liu, L., Friston, K. J., Shen, H., Wang, L., Zeng, L.-L., et al. (2013). A treatment-resistant default mode subnetwork in major depression. Biol. Psychiatry 74, 48-54. doi: 10.1016/j.biopsych.2012.11.007

Li, W., Antuono, P. G., Xie, C., Chen, G., Jones, J. L., Ward, B. D., et al. (2012). Changes in regional cerebral blood flow and functional connectivity in the cholinergic pathway associated with cognitive performance in subjects with mild Alzheimer's disease after 12-week donepezil treatment. Neuroimage 60, 1083-1091. doi: 10.1016/j.neuroimage.2011.12.077

Liao, W., Zhang, Z., Pan, Z., Mantini, D., Ding, J., Duan, X., et al. (2010). Default mode network abnormalities in mesial temporal lobe epilepsy: a study combining fMRI and DTI. Hum. Brain Mapp. 32, 883-895. doi: 10.1002/hbm. 21076

Liu, C.-H., Ma, X., Wu, X., Zhang, Y., Zhou, F.-C., Li, F., et al. (2013). Regional homogeneity of resting-state brain abnormalities in bipolar and unipolar 
depression. Progr. Neuro Psychopharmacol. Biol. Psychiatry 41, 52-59. doi: 10.1016/j.pnpbp.2012.11.010

Luders, E., Toga, A. W., Lepore, N., and Gaser, C. (2009). The underlying anatomical correlates of long-term meditation: larger hippocampal and frontal volumes of gray matter. Neuroimage 45, 672-678. doi: 10.1016/j.neuroimage.2008.12.061

Ludwig, D. S., and Kabat-Zinn, J. (2008). Mindfulness in medicine. J. Am. Med. Assoc. 300, 1350-1352. doi: 10.1001/jama.300.11.1350

Lui, S., Wu, Q., Qiu, L., Yang, X., Kuang, W., Chan, R. C. K., et al. (2011). Resting-state functional connectivity in treatment-resistant depression. Am. J. Psychiatry 168, 642-648. doi: 10.1176/appi.ajp.2010.10101419

Lutz, A., Dunne, J. D., and Davidson, R. J. (2007). "Meditation and the neuroscience of consciousness: an introduction," in Cambridge Handbook of Consciousness, eds P. D. Zelazo, M. Moscovitch and E. Thompson (Cambridge, MA: Cambridge University Press), 499-551.

Lutz, A., Greischar, L. L., Rawlings, N. B., Ricard, M., and Davidson, R. J. (2004). Long-term meditators self-induce high-amplitude gamma synchrony during mental practice. Proc. Natl. Acad. Sci. U.S.A. 101, 16369-16373. doi: 10.1073/pnas.0407401101

Lutz, A., Slagter, H. A., Dunne, J. D., and Davidson, R. J. (2008). Attention regulation and monitoring in meditation. Trends Cogn. Sci. 12, 163-169. doi: 10.1016/j.tics.2008.01.005

Lutz, J., Herwig, U., Opialla, S., Hittmeyer, A., Jancke, L., Rufer, M., et al. (2014). Mindfulness and emotion regulation-an fMRI study. Soc. Cogn. Affect. Neurosci. 9, 776-785. doi: 10.1093/scan/nst043

Ma, S. H., and Teasdale, J. D. (2004). Mindfulness-based cognitive therapy for depression: replication and exploration of differential relapse prevention effects. J. Consult. Clin. Psychol. 72, 31. doi: 10.1037/0022-006X.72.1.31

MacCoon, D. G., Imel, Z. E., Rosenkranz, M. A., Sheftel, J. G., Weng, H. Y., Sullivan, J. C., et al. (2012). The validation of an active control intervention for mindfulness based stress reduction (MBSR). Behav. Res. Ther. 50, 3-12. doi: 10.1016/j.brat.2011.10.011

MacCoon, D. G., MacLean, K. A., Davidson, R. J., Saron, C. D., and Lutz, A. (2014). No sustained attention differences in a longitudinal randomized trial comparing mindfulness based stress reduction versus active control. PLoS ONE 9:e97551. doi: 10.1371/journal.pone.0097551

Manna, A., Raffone, A., Perrucci, M. G., Nardo, D., Ferretti, A., Tartaro, A., et al. (2010). Neural correlates of focused attention and cognitive monitoring in meditation. Brain Res. Bull. 82, 46-56. doi: 10.1016/j.brainresbull.2010. 03.001

Mason, M. F., Norton, M. I., Van Horn, J. D., Wegner, D. M., Grafton, S. T., and Macrae, C. N. (2007). Wandering minds: the default network and stimulus-independent thought. Science 315, 393-395. doi: 10.1126/science.11 31295

Mazoyer, B., Zago, L., Mellet, E., Bricogne, S., Etard, O., Houde, O., et al. (2001). Cortical networks for working memory and executive functions sustain the conscious resting state in man. Brain Res. Bull. 54, 287-298. doi: 10.1016/S03619230(00)00437-8

Pagnoni, G. (2012). Dynamical properties of BOLD activity from the ventral posteromedial cortex associated with meditation and attentional skills J. Neurosci. 32, 5242-5249. doi: 10.1523/JNEUROSCI.4135-11.2012

Pomarol-Clotet, E., Salvador, R., Sarro, S., Gomar, J., Vila, F., Martinez, A., et al. (2008). Failure to deactivate in the prefrontal cortex in schizophrenia: dysfunction of the default mode network? Psychol. Med. 38, 1185-1193. doi: $10.1017 /$ S0033291708003565

Posner, J., Hellerstein, D. J., Gat, I., Mechling, A., Klahr, K., Wang, Z., et al. (2013). Antidepressants normalize the default mode network in patients with dysthymia. JAMA Psychiatry 70, 373-382. doi: 10.1001/jamapsychiatry.2013.455

Raichle, M. E., MacLeod, A. M., Snyder, A. Z., Powers, W. J., Gusnard, D. A., and Shulman, G. L. (2001). A default mode of brain function. Proc. Natl. Acad. Sci. U.S.A. 98, 676-682. doi: 10.1073/pnas.98.2.676

Raichle, M. E., and Mintun, M. A. (2006). Brain work and brain imaging. Annu. Rev. Neurosci. 29, 449-476. doi: 10.1146/annurev.neuro.29.051605.112819

Raichle, M. E., and Snyder, A. Z. (2007). A default mode of brain function: a brief history of an evolving idea. Neuroimage 37, 1083-1090. doi: 10.1016/j.neuroimage.2007.02.041

Rosenkranz, M. A., Davidson, R. J., MacCoon, D. G., Sheridan, J. F., Kalin, N. H., and Lutz, A. (2013). A comparison of mindfulness-based stress reduction and an active control in modulation of neurogenic inflammation. Brain Behav. Immun. 27, 174-184. doi: 10.1016/j.bbi.2012.10.013

Safran, J. (1990). Towards a refinement of cognitive therapy in light of interpersonal theory: I. Theory. Clin. Psychol. Rev. 10, 87-105. doi: 10.1016/0272-7358(90)90108-M

Sambataro, F., Blasi, G., Fazio, L., Caforio, G., Taurisano, P., Romano, R., et al. (2009). Treatment with olanzapine is associated with modulation of the default mode network in patients with schizophrenia. Neuropsychopharmacology 35, 904-912. doi: 10.1038/npp.2009.192

Seitz, R. J., Nickel, J., and Azari, N. P. (2006). Functional modularity of the medial prefrontal cortex: involvement in human empathy. Neuropsychology 20, 743. doi: 10.1037/0894-4105.20.6.743

Shapiro, S. L., Carlson, L. E., Astin, J. A., and Freedman, B. (2006). Mechanisms of mindfulness. J. Clin. Psychol. 62, 373-386. doi: 10.1002/jclp. 20237

Sheline, Y. I., Barch, D. M., Price, J. L., Rundle, M. M., Vaishnavi, S. N., Snyder, A. Z., et al. (2009). The default mode network and self-referential processes in depression. Proc. Natl. Acad. Sci. U.S.A. 106, 1942-1947. doi: 10.1073/pnas.0812686106

Sheline, Y. I., Price, J. L., Yan, Z., and Mintun, M. A. (2010a). Restingstate functional MRI in depression unmasks increased connectivity between networks via the dorsal nexus. Proc. Natl. Acad. Sci. U.S.A. 107, 11020-11025. doi: 10.1073/pnas.1000446107

Sheline, Y. I., Raichle, M. E., Snyder, A. Z., Morris, J. C., Head, D., Wang, S., et al. (2010b). Amyloid plaques disrupt resting state default mode network connectivity in cognitively normal elderly. Biol. Psychiatry 67, 584-587. doi: 10.1016/j.biopsych.2009.08.024

Sheline, Y. I., and Raichle, M. E. (2013). Resting state functional connectivity in preclinical Alzheimer's disease. Biol. Psychiatry 74, 340-347. doi: 10.1016/j.biopsych.2012.11.028

Shen, H., Li, Z., Zeng, L.-L., Yuan, L., Chen, F., Liu, Z., et al. (2014). Internetwork dynamic connectivity effectively differentiates schizophrenic patients from healthy controls. Neuroreport 25, 1344-1349. doi: 10.1097/WNR.0000000000000267

Shonin, E., Van Gordon, W., Compare, A., Zangeneh, M., and Griffiths, M. D. (2014). Buddhist-derived loving-kindness and compassion meditation for the treatment of psychopathology: a systematic review. Mindfulness doi: 10.1007/s12671-014-0368-1

Shulman, G. L., Fiez, J. A., Corbetta, M., Buckner, R. L., Miezin, F. M., Raichle, M. E., et al. (1997). Common blood flow changes across visual tasks: II. Decreases in cerebral cortex. J. Cogn. Neurosci. 9, 648-663. doi: 10.1162/jocn.1997.9.5.648

Shulman, R. G., Rothman, D. L., Behar, K. L., and Hyder, F. (2004). Energetic basis of brain activity: implications for neuroimaging. Trends Neurosci. 27, 489-495. doi: 10.1016/j.tins.2004.06.005

Smalley, S. L., Loo, S. K., Hale, T. S., Shrestha, A., McGough, J., Flook, L., et al. (2009). Mindfulness and attention deficit hyperactivity disorder. J. Clin. Psychol. 65, 1087-1098. doi: 10.1002/jclp.20618

Smucny, J., Wylie, K. P., and Tregellas, J. R. (2014). Functional magnetic resonance imaging of intrinsic brain networks for translational drug discovery. Trends Pharmacol. Sci. 35, 397-403. doi: 10.1016/j.tips.2014. 05.001

Sonuga-Barke, E. J. S., and Castellanos, F. X. (2007). Spontaneous attentional fluctuations in impaired states and pathological conditions: a neurobiological hypothesis. Neurosci. Biobehav. Rev. 31, 977-986. doi: 10.1016/j.neubiorev.2007.02.005

Sorg, C., Riedl, V., Mühlau, M., Calhoun, V. D., Eichele, T., Läer, L., et al. (2007). Selective changes of resting-state networks in individuals at risk for Alzheimer's disease. Proc. Natl. Acad. Sci. U.S.A. 104, 18760-18765. doi: 10.1073/pnas.0708803104

Spencer, M. D., Chura, L. R., Holt, R. J., Suckling, J., Calder, A. J., Bullmore, E. T., et al. (2012). Failure to deactivate the default mode network indicates a possible endophenotype of autism. Mol. Autism. 3, 15. doi: 10.1186/2040-23 92-3-15

Sperling, R. (2011). The potential of functional MRI as a biomarker in early Alzheimer's disease. Neurobiol. Aging 32, S37-S43. doi: 10.1016/j.neurobiolaging.2011.09.009

Tang, Y.-Y., Hölzel, B. K., and Posner, M. I. (2015). The neuroscience of mindfulness meditation. Nat. Rev. Neurosci. 16, 213-225. doi: 10.1038/nrn3916 
Tang, Y. Y., Lu, Q., Fan, M., Yang, Y., and Posner, M. I. (2012). Mechanisms of white matter changes induced by meditation. Proc. Natl. Acad. Sci. U.S.A. 109, 10570-10574. doi: 10.1073/pnas.1207817109

Tang, Y.-Y., Posner, M. I., and Rothbart, M. K. (2014). Meditation improves self-regulation over the life span. Ann. N. Y. Acad. Sci. 1307, 104-111. doi: $10.1111 /$ nyas. 12227

Taylor, V. A., Daneault, V., Grant, J., Scavone, G., Breton, E., Roffe-Vidal, S., et al. (2013). Impact of meditation training on the default mode network during a restful state. Soc. Cogn. Affect. Neurosci. 8, 4-14. doi: 10.1093/scan/ nsr087

Teasdale, J. D., Segal, Z. V., Williams, J. M. G., Ridgeway, V. A., Soulsby, J. M., and Lau, M. A. (2000). Prevention of relapse/recurrence in major depression by mindfulness-based cognitive therapy. J. Consult. Clin. Psychol. 68, 615-623. doi: 10.1037//0022-006X.68.4.615

Tomasino, B., Chiesa, A., and Fabbro, F. (2014). Disentangling the neural mechanisms involved in Hinduism- and Buddhism-related meditations. Brain Cogn. 90, 32-40. doi: 10.1016/j.bandc.2014.03.013

Tomasino, B., Fregona, S., Skrap, M., and Fabbro, F. (2012). Meditation-related activations are modulated by the practices needed to obtain it and by the expertise: an ALE meta-analysis study. Front. Hum. Neurosci. 6:346. doi: 10.3389/fnhum.2012.00346

Tregellas, J. R., Tanabe, J., Rojas, D. C., Shatti, S., Olincy, A., Johnson, L., et al. (2011). Effects of an alpha 7-nicotinic agonist on default network activity in schizophrenia. Biol. Psychiatry 69, 7-11. doi: 10.1016/j.biopsych.2010.07.004

Uddin, L. Q., Kelly, A. C., Biswal, B. B., Margulies, D. S., Shehzad, Z., Shaw, D., et al. (2008). Network homogeneity reveals decreased integrity of default-mode network in ADHD. J. Neurosci. Methods 169, 249-254. doi: 10.1016/j.jneumeth.2007.11.031

Völlm, B. A., Taylor, A. N., Richardson, P., Corcoran, R., Stirling, J., McKie, S. et al. (2006). Neuronal correlates of theory of mind and empathy: a functional magnetic resonance imaging study in a nonverbal task. Neuroimage 29, 90-98. doi: 10.1016/j.neuroimage.2005.07.022

Wang, L., Xia, M., Li, K., Zeng, Y., Su, Y., Dai, W., et al. (2014). The effects of antidepressant treatment on resting-state functional brain networks in patients with major depressive disorder. Hum. Brain Mapp. 36, 768-778. doi: 10.1002/hbm. 22663

Weissman, D. H., Roberts, K. C., Visscher, K. M., and Woldorff, M. G. (2006). The neural bases of momentary lapses in attention. Nat. Neurosci. 9, 971-978. doi: $10.1038 / \mathrm{nn} 1727$

Wells, R. E., Kerr, C. E., Wolkin, J., Dossett, M., Davis, R. B., Walsh, J., et al. (2013a). Meditation for adults with mild cognitive impairment: a pilot randomized trial. J. Am. Geriatr. Soc. 61, 642-645. doi: 10.1111/jgs. 12179
Wells, R. E., Yeh, G. Y., Kerr, C. E., Wolkin, J., Davis, R. B., Tan, Y., et al. (2013b). Meditation's impact on default mode network and hippocampus in mild cognitive impairment: a pilot study. Neurosci. Lett. 556, 15-19. doi: 10.1016/j.neulet.2013.10.001

Whitfield-Gabrieli, S., and Ford, J. M. (2012). Default mode network activity and connectivity in psychopathology. Annu. Rev. Clin. Psychol. 8, 49-76. doi: 10.1146/annurev-clinpsy-032511-143049

Whitfield-Gabrieli, S., Thermenos, H. W., Milanovic, S., Tsuang, M. T., Faraone, S. V., McCarley, R. W., et al. (2009). Hyperactivity and hyperconnectivity of the default network in schizophrenia and in first-degree relatives of persons with schizophrenia. Proc. Natl. Acad. Sci. U.S.A. 106, 1279-1284. doi: 10.1073/pnas.0809141106

Wise, T., Cleare, A. J., Herane, A., Young, A. H., and Arnone, D. (2014). Diagnostic and therapeutic utility of neuroimaging in depression: an overview. Neuropsychiatr. Dis. Treat. 10, 1509-1522. doi: 10.2147/NDT.S50156

Witkiewitz, K., Marlatt, G. A., and Walker, D. (2005). Mindfulness-based relapse prevention for alcohol and substance use disorders. J. Cogn. Psychother. 19, 211-228. doi: 10.1891/jcop.2005.19.3.211

Xu, J., Vik, A., Groote, I. R., Lagopoulos, J., Holen, A., Ellingsen, Ø., et al. (2014). Nondirective meditation activates default mode network and areas associated with memory retrieval and emotional processing. Front. Hum. Neurosci. 8:26. doi: 10.3389/fnhum.2014.00086

Zeidan, F., Johnson, S. K., Diamond, B. J., David, Z., and Goolkasian, P. (2010). Mindfulness meditation improves cognition: evidence of brief mental training. Conscious. Cogn. 19, 597-605. doi: 10.1016/j.concog.2010.03.014

Zhao, X.-H., Wang, P.-J., Li, C.-B., Hu, Z.-H., Xi, Q., Wu, W.-Y., et al. (2007). Altered default mode network activity in patient with anxiety disorders: an fMRI study. Eur. J. Radiol. 63, 373-378. doi: 10.1016/j.ejrad.2007.02.006

Zylowska, L., Ackerman, D. L., Yang, M. H., Futrell, J. L., Horton, N. L., Hale, T. S., et al. (2007). Mindfulness meditation training in adults and adolescents With ADHD: a feasibility study. J. Atten. Disord. 11, 737-746. doi: $10.1177 / 1087054707308502$

Conflict of Interest Statement: The authors declare that the research was conducted in the absence of any commercial or financial relationships that could be construed as a potential conflict of interest.

Copyright (C) 2015 Simon and Engström. This is an open-access article distributed under the terms of the Creative Commons Attribution License (CC BY). The use, distribution or reproduction in other forums is permitted, provided the original author(s) or licensor are credited and that the original publication in this journal is cited, in accordance with accepted academic practice. No use, distribution or reproduction is permitted which does not comply with these terms. 